\title{
Targeting Schlemm's Canal in the Medical Therapy of Glaucoma: Current and Future Considerations
}

\author{
Vanessa Andrés-Guerrero · Julián García-Feijoo · Anastasios Georgios Konstas
}

Received: February 2, 2017 / Published online: March 27, 2017

(C) The Author(s) 2017. This article is an open access publication

\begin{abstract}
Schlemm's canal (SC) is a unique, complex vascular structure responsible for maintaining fluid homeostasis within the anterior segment of the eye by draining the excess of aqueous humour. In glaucoma, a heterogeneous group of eye disorders afflicting approximately 60 million individuals worldwide, the normal outflow of aqueous humour into SC is progressively hindered, leading to a gradual increase in outflow resistance, which gradually results in
\end{abstract}

Enhanced content To view enhanced content for this article go to http://www.medengine.com/Redeem/ A3F7F060182254BF.

V. Andrés-Guerrero · J. García-Feijoo Department of Ophthalmology, Sanitary Research Institute of the San Carlos Clinical Hospital, Madrid, Spain

V. Andrés-Guerrero · J. García-Feijoo Ocular Pathology National Net OftaRed of the Institute of Health Carlos III, Madrid, Spain

J. García-Feijoo

Department of Ophthalmology, Faculty of Medicine, Complutense University of Madrid, Madrid, Spain

A. G. Konstas ( $\square)$

1st and 3rd University Departments of Ophthalmology, AHEPA Hospital, Aristotle

University of Thessaloniki, 1 Kyriakidi Street, 54636

Thessaloniki, Greece

e-mail: konstas@med.auth.gr elevated intraocular pressure (IOP). By and large available antiglaucoma therapies do not target the site of the pathology (SC), but rather aim to decrease IOP by other mechanisms, either reducing aqueous production or by diverting aqueous flow through the unconventional outflow system. The present review first outlines our current understanding on the functional anatomy of SC. It then summarizes existing research on SC cell properties; first in the context of their role in glaucoma development/ progression and then as a target of novel and emerging antiglaucoma therapies. Evidence from ongoing research efforts to develop effective antiglaucoma therapies targeting SC suggests that this could become a promising site of future therapeutic interventions.

Keywords: Actin polymerization inhibitors; Adenosine receptor agonists; Antiglaucoma drug development; Aqueous humour; Glaucoma; Intraocular pressure; Nitric oxide donors; Ophthalmology; Rho Kinase inhibitors; Schlemm's canal

\section{INTRODUCTION}

Glaucoma is a group of chronic, multifactorial, and progressive eye disorders that eventually lead to damage of the optic nerve and irreversible visual loss. Given the progressive ageing 
of the world's population, the number of individuals affected by glaucoma is projected to increase to almost 80 million by 2020 [1]. Consequently, there is a pressing need for the development of novel therapies, which will not only reduce intraocular pressure (IOP) as current therapies generally do but which will also prevent glaucoma development and slow down its progression. To succeed this requires innovative biological interventions that will positively modify the various pathophysiological processes involved in glaucoma pathogenesis.

In glaucoma, it is established that there is an impaired balance between deposition and degradation of extracellular matrix material (ECM) within the trabecular meshwork (TM). Gradual accumulation of ECM within the outflow system is thought to result in a functional obstruction leading to a gradual, asymptomatic elevation of intraocular pressure (IOP) [2]. Elevated IOP is at present the most important modifiable risk factor for the onset and progression of glaucoma. The elevation of IOP may compress TM and result in a collapse of Schlemm's canal (SC), pathological steps which also increase outflow resistance and contribute to the pathobiology of glaucoma development [3].

At the present time, available glaucoma therapies aim to obtain a meaningful IOP reduction to a predetermined target IOP level. This is achieved by the selection of one or more classes of topical medications, which are administered every day in order to meaningfully reduce 24-h IOP. Existing antiglaucoma therapies either reduce IOP by decreasing aqueous synthesis ( $\beta$-blockers, carbonic anhydrase inhibitors, alpha agonists) or target and enhance the unconventional uveoscleral outflow pathway (prostaglandins). Sadly, contemporary glaucoma medications do not target the conventional outflow system (TM and SC), which is the site of glaucomatous pathobiology and the site of anatomical and functional outflow obstruction. Drugs that have been shown to improve conventional outflow have either been abandoned due to unacceptable side effects (cholinergics, e.g. pilocarpine), or have a minimal impact on this outflow site (e.g. brimonidine) [4]. It would therefore appear logical to develop in the future therapies that target the conventional outflow system. Moreover, it is not uncommon for available medical therapies to not sufficiently control IOP. This is due to their inability to reach an optimal balance between long-term efficacy, tolerability and adherence. New medications targeting the conventional outflow system may provide adjunctive IOP reduction with superior tolerability allowing a more successful medical antiglaucoma therapy. This review first summarizes recent advancements in our undestanding on SC cell properties and their contributing role in glaucoma development and progression. Then, it discusses and explores the clinical value of targeting SC to better manage glaucoma in the future.

This article is based on previously conducted studies, and does not involve any new studies of human or animal subjects performed by any of the authors.

\section{REGULATION OF AQUEOUS HUMOUR DYNAMICS}

Aqueous humour fills the space between the cornea and the lens, providing nutrients to these avascular structures that must remain clear to allow light transmission. It stabilizes ocular structures, transports neurotransmitters, provides nutrition, and removes metabolic by-products, significantly contributing to the regulation of ocular tissue homeostasis. The average rate of production of $\mathrm{AH}$ is 2.0-2.5 $\mu \mathrm{L} \min ^{-1}$, and the turnover rate for aqueous volume is approximately $1 \%$ per minute [5]. Fluctuations in either the synthesis, or more commonly, the drainage of aqueous can be responsible for an elevation in IOP. The aqueous is constantly produced by three mechanisms: active secretion, diffusion and ultrafiltration [6]. The most important mechanism is active secretion, mediated by protein transporters and enzymes, such as $\mathrm{Na}^{+}-\mathrm{K}^{+}$-ATPase and carbonic anhydrase, both located in the non-pigmented and pigmented ciliary epithelia [7]. This process is responsible for approximately $80-90 \%$ of the total aqueous formation, and occurs through selective 
trans-cellular movement of anions, cations, and other molecules across a concentration gradient in the blood-aqueous barrier. The synthesis by diffusion comprises the pass of solutes-mainly hydrophobic-through the lipid portions of the membrane of the tissues, between the capillaries and the posterior chamber, this process being proportional to a concentration gradient across the membrane [8]. The ultrafiltration mechanism refers to the flow of water and hydrophilic substances across fenestrated ciliary capillary endothelia into the ciliary stroma, depending on an osmotic gradient or hydrostatic pressure [8].

The continuous synthesis of aqueous humour must be balanced by sufficient aqueous drainage through the TM into SC and then back to the systemic circulation. This systematic continuous drainage is named the conventional outflow pathway and comprises beyond the TM, the juxtacanalicular connective tissue, the endothelial lining of $\mathrm{SC}$, the collecting channels, and the aqueous veins. This pathway provides resistance to aqueous outflow; in response to this resistance the IOP gradually rises to a level sufficient to allow the flow of aqueous across the TM into SC [9]. Thus, aqueous passes through the TM as a bulk flow driven by the pressure gradient. At steady-state IOP, aqueous flow rate across the TM resistance equals the rate of aqueous synthesis by the ciliary body. Alternative outflow is provided by the unconventional uveoscleral pathway where the flow is pressure-independent and a proportion of aqueous humour leaves the eye through the interstitial spaces of the ciliary body.

\section{SCHLEMM'S CANAL ANATOMY}

SC is located at the inner space of the corneoscleral junction, encircling the cornea, and is responsible for controlling the balance between secretion and drainage of the aqueous after it crosses the TM. Filled with blood, deriving from the ipsilateral episcleral or jugular vein, SC appears as an irregular red line with a varying diameter, divided by partitions into small tributaries, which join together in a plexiform appearance. In a cross-section, SC appears as a flattened oval structure between the sclera spur and Descemet's membrane, bounded anterolaterally by the sclera and posteriorly by the corneoscleral trabeculae. The canal can be divided into three zones: the endothelial lining, the basal lamina, and the peri- or juxta-canalicular connective tissue [10]. The endothelial lining is formed by a single layer of delicate spindle-shaped endothelial cells with wedge-shaped, rounded ends, which are located parallel to the circumference of the canal. The endothelial cells show small microvilli on their apical area, a few projections extended into the basement membrane in the basal area, and gap junctions and complex interdigitations between adjacent and lateral cells [11]. Endothelial cells contain an elongated nucleus, mitochondria, rough and smooth endoplasmic reticulum, golgi apparatus, centrosomes, and pinocytic vesicles, as well as fine cytoplasmic filaments and giant vacuolar configurations, which are believed to play a major role in the bulk outflow of aqueous across the endothelial barrier [12].

The basement membrane is composed of an amorphous matrix of an irregular network of thin microfibril loose sheets, provides anchorage to SC endothelial lining. The basement membrane is separated from the outermost part of the TM by the pericanalicular connective tissue [13]. The extracellular spaces of the connective tissue are narrower than those of the TM and contain hydrophilic glycosaminoglycans and collagenous material, causing aqueous outflow resistance and obstructing particulate material [9]. The basement membrane consists of loosely arranged mesothelial cells and fixed endothelial cells, whose ultrastructure appears similar to that of the endothelial lining and fibrous tissues, such as collagen fibrils, elastic fibers, basement membrane material, microfibrils, and curly collagen. Fixed endothelial cells have active phagocytic function and show shrinking and swelling properties, being able to alter the porosity of this region and thus participating in IOP modulation [12]. 


\section{SCHLEMM'S CANAL BIOMECHANICS IN GLAUCOMA}

As discussed above, the conventional aqueous pathway consists of the TM, the juxtacanalicular connective tissue, the endothelial lining of $\mathrm{SC}$, the collecting channels, and the aqueous veins, in this order. Among these structures, it is established that SC offers the greatest resistance to aqueous outflow, providing a promising option for the development of IOP-lowering therapies. The resistance induced at the SC level is predominantly due to the compact endothelial cell lining, composed by a single layer of spindle-shaped cells joined with numerous tight junctions and complex interdigitations between adjacent and lateral cells [11]. Although even today the precise mechanism delineating aqueous drainage is not completely understood, a key process involved is cytoplasmic vacuole formation and migration, which drains aqueous from the TM through the juxtacanalicular tissue and the endothelial monolayer, into the lumen of SC [14]. Giant vacuoles are formed in response to the pressure gradient created by aqueous flow. Most vacuoles demonstrate a large opening on the meshwork side of the vacuole and around one-third also have a distal opening, forming transcellular and paracellular pores [15]. Transcellular pores pass from the basal side of the cell to the apical side at a location on the cell surface where the inner and outer surfaces of the cell are joined together and are fused. The high hydraulic conductivity of SC appears to be related to the presence of a large number of these pores, whose diameter ranges between 0.1 and $2 \mu \mathrm{m}$ [14]. With regard to the paracellular pores, they appear to correlate well with the paracellular flow through SC endothelium [9]. Small minipores, covered with a thin diaphragm and with a diameter ranging from 60 to $65 \mathrm{~nm}$, have also been identified in the SC inner wall endothelium. Minipores have similar ultrastructural characteristics to those forming the fenestrated capillaries in the ciliary body, or choroid, and thus it has been hypothesized that they are the origin of large transcellular pores [16].
A number of researchers have investigated the relationship between pore density in SC endothelium and aqueous humour facility, in order to determine a possible relationship between pore number in glaucomatous and normal eyes [17-19]. However, due to methodological differences arising from the fixation procedure employed, and the fact that pore density increases with the volume of fixative perfused through the outflow pathway [20], results in glaucomatous eyes have been inconsistent. This has generated controversy as to the precise role of inner wall pores in outflow facility. Despite this, recent studies have attempted to compare pore density in normal and glaucomatous eyes. Johnson et al. [19] established a correlation in the density of intracellular and border pores between normal and glaucomatous eyes after correction for the effects of fixation conditions. They reported that, even after accounting for the volume of fixative perfused, glaucomatous eyes exhibit only $20 \%$ of the pore density seen in normal eyes (160 vs. 835 pores $/ \mathrm{mm}^{2}$, respectively). Consequently, these authors suggested that this phenomenon may explain the IOP elevation seen in glaucoma [19]. In 2014, Braakman et al. [21] perfused fluorescent tracer nanospheres in non-glaucomatous human donor eyes to experimentally describe local patterns of outflow segmentation through the conventional route. By confocal and scanning electron microscopy, they examined the spatial relationship between inner wall pore density and tracer intensity. Their results suggested that the aqueous passed through micron-sized pores in the inner wall endothelium of $\mathrm{SC}$, and that paracellular pores played a major role in transendothelial filtration across the inner wall in comparison to transcellular pores. The spatial correlation between pores and tracer suggested that pores influenced outflow segmentation, but no insight was offered into the precise nature of this relationship. These investigators [21] speculated that the physiological situation represented a coupled interaction between local filtration demands and the cellular biomechanics involved in giant vacuole and pore formation. 
In SC cells, vacuole and pore formation is dependent on pressure and is most likely related to tissue stiffness. Tissue and cell stiffness are factors that may significantly modify the responsiveness of the TM and SC to normal fluid flow, pressure, and shear stress. Overby et al. [22] reported that pore formation correlated with the stiffness of the subcortical cytoskeleton in SC cells as well as that glaucomatous SC cells exhibited both a stiffer subcortical cytoskeleton and a reduced ability to form pores. It has been recognized that SC stiffness is influenced by drug therapies affecting outflow. Specifically, when a drug stiffened SC cells, resistance increased, and when a drug therapy relaxed these cells, outflow resistance decreased. These observations suggest that those drugs that will directly or indirectly modify the cytoskeleton will decrease cell stiffness and result in reduced outflow resistance [23-27].

The endothelial lining of SC demonstrates both blood and lymphatic vascular characteristics, calling into question the longstanding dogma that the eye lacks lymphatic vessels. Several years ago, lymphatic markers were identified in the anterior segment and ciliary body of the human eye. Nevertheless, it was not clear whether they were actively involved in the maintenance of ocular fluid homeostasis $[28,29]$. In a recent study, Hoopes et al. [30] found that temporal delection of Calcrl, a highly expressed receptor in lymphatic endothelial cells, resulted in dilated corneoscleral lymphatic vessels that preceded and were associated with the formation of corneal edema and inflammation. Hence, these results suggested that lymphatic vessels may contribute to the maintenance of fluid homeostasis and corneal hydration [30]. More recently, Truong et al. [31] provided the first evidence showing the expression of the lymphatic marker Prox-1 on SC endothelium, indicating its closer similarities with lymphatic endothelium than with blood endothelium. Likewise, authors employed a panel of protein markers that allowed a better identification, isolation, and characterization of SC endothelial cells, resulting in improved endothelial cell harvesting efficiency. Therefore, stimulation of SC with lymphatic-specific therapies may result in a significant lowering of IOP and could constitute a promising approach in future glaucoma treatment.

\section{TARGETING SCHLEMM'S CANAL TO REDUCE IOP}

The precise biomechanics of the resistance to aqueous humour flow through the conventional outflow pathway is a subject still under investigation. However, the most popular hypothesis is that the contractile status of cells in the aqueous pathway regulate outflow resistance with a key role played by cell stiffness [32-37]. It is established that drugs such as bradykinin, dexamethasone, or triamcinolone are capable of increasing cell stiffness and by doing so augment outflow resistance, while other drugs decrease outflow resistance by relaxing SC cells [12]. In glaucomatous eyes, SC cells are more sensitive to substrate stiffness than normal, age-matched SC cells [38], modifying the expression of genes implicated in outflow obstruction and glaucoma in response to changes in substrate stiffness, such as the connective tissue growth factor CTGF [33]. Consequently, targeting the SC level of stiffness and enhancing outflow facility would appear to be a promising anti-glaucoma strategy. Further, this would appear a logical step: decreasing outflow resistance at the conventional outflow pathway which is known to be responsible for regulating the majority of aqueous humour outflow. The effectiveness of several IOP-lowering therapies that focus on the mechanisms underlying ECM turnover and cell stiffness has already been successfully demonstrated. These include adenosine A1 receptor agonists [39-45], nitric oxide donors [12, 46-48], Rho Kinase inhibitors [49] and actin depolymerizers (Tables 1, 2) [23, 25, 26, 50-53].

\section{Adenosine Receptor Agonists}

Adenosine is a nucleoside modulator and a common signaling molecule associated with cellular responses to stressful situations, such as eye ischemia that can lead to a rapid elevation 
Table 1 Summary of new drugs included in the review that have been employed in preclinical studies to reduce intraocular pressure in glaucoma by targeting the conventional outflow system

\begin{tabular}{|c|c|c|c|c|}
\hline Type & $\begin{array}{l}\text { Proposed mechanism of } \\
\text { action }\end{array}$ & Effect & $\begin{array}{l}\text { Experimental } \\
\text { drug }\end{array}$ & References \\
\hline $\begin{array}{l}\text { Adenosine } \\
\text { receptor } \\
\text { agonists }\end{array}$ & $\begin{array}{l}\text { Stimulation of adenosine } \\
\text { receptors on trabecular cells. }\end{array}$ & $\begin{array}{l}\text { The activation of these } \\
\text { receptors leads to secretion } \\
\text { of matrix-degrading } \\
\text { enzymes. }\end{array}$ & $\begin{array}{l}\text { R-PIA } \\
\text { Trabodenoson }\end{array}$ & $\begin{array}{l}{[40,41]} \\
{[92,93]}\end{array}$ \\
\hline $\begin{array}{l}\text { Nitric oxide } \\
\text { donors }\end{array}$ & $\begin{array}{l}\text { Homeostatic signaling } \\
\text { function on trabecular and } \\
\text { Schlemm's canal cells. }\end{array}$ & $\begin{array}{l}\text { Modulation of cell response } \\
\text { to shear stress during times } \\
\text { of elevated IOP. }\end{array}$ & $\begin{array}{l}\text { NCX } 125 \\
\text { BOL-303259-X } \\
\text { NCX } 470\end{array}$ & $\begin{array}{l}{[46]} \\
{[47]} \\
{[48]}\end{array}$ \\
\hline $\begin{array}{r}\text { Rho Kinase } \\
\text { inhibitors }\end{array}$ & $\begin{array}{l}\text { Inhibition of myosin light } \\
\text { chain phosphatase on } \\
\text { trabecular and Schlemm's } \\
\text { canal cells. }\end{array}$ & $\begin{array}{l}\text { Actin cytoskeletal changes in } \\
\text { cells that influence the } \\
\text { contractile properties of } \\
\text { tissues. }\end{array}$ & $\begin{array}{l}\text { Y-27632 } \\
\text { HA-1077 } \\
\text { H-1152P } \\
\text { Compound } 38 \\
\text { Compound 1y } \\
\text { AMA0076 } \\
\text { K-115 }\end{array}$ & $\begin{array}{l}{[79,80]} \\
{[81]} \\
{[82]} \\
{[83]} \\
{[84]} \\
{[85]} \\
{[101]}\end{array}$ \\
\hline $\begin{array}{l}\text { Actin } \\
\text { polymerization } \\
\text { inhibitors }\end{array}$ & $\begin{array}{l}\text { Actin depolymerizers on } \\
\text { trabecular and Schlemm's } \\
\text { canal cells. }\end{array}$ & $\begin{array}{l}\text { Cell morphology alterations } \\
\text { that enlarge openings } \\
\text { between cells. }\end{array}$ & $\begin{array}{l}\text { Cytochalasin D } \\
\text { Latrunculin }\end{array}$ & $\begin{array}{l}{[89]} \\
{[25,26,50,52,89]}\end{array}$ \\
\hline
\end{tabular}

of adenosine concentration [54]. In the cell, adenosine is detected in the cytosol; in the extracellular space adenosine is produced from ATP, which gets dephosphorylated to AMP and subsequently to adenosine [55]. The enzymes involved in the production of adenosine are ecto-nucleotidases, which are expressed in the choroid, ciliary body processes and TM [56-58]. Elevated ATP levels in the aqueous humour have been associated with primary angle-closure glaucoma and chronic angle-closure glaucoma $[59,60]$. While the mean aqueous adenosine concentration in healthy eyes is around $200 \mathrm{nM}$, in ocular hypertension its concentration rises to $500 \mathrm{nM}$, showing a significant correlation with elevated IOP $[59,61]$. Studies have shown that the effect of adenosine receptor stimulation on IOP is species-specific. However, in general, the stimulation of adenosine A1 receptors lowers IOP in all species [62]. In rabbits, mice, and monkeys, the use of adenosine A1 agonists has effectively reduced IOP [39-43], generating both a decrease in aqueous flow and an increase in outflow facility [40, 41, 43]. Further, Shearer and Crosson [44] provided convincing evidence for the presence of adenosine A1 receptors on trabecular cells. These authors concluded that the activation of these receptors leads to a rapid secretion of MMP-2, and supported the notion that the increase in outflow facility involves the activation of adenosine A1 receptors on TM cells.

In vivo studies in rabbits have shown that the topical administration of the relatively selective A1 adenosine receptor agonist R-phenylsopropyladenosine (R-PIA) produced a biphasic effect, with a $8.4-\mathrm{mm} \mathrm{Hg}$ rise at $30 \mathrm{~min}$ and a maximum IOP reduction of 
Table 2 Summary of clinical trials included in the review to evaluate new medications targeting the conventional outflow system, for the treatment of ocular hypertension in glaucoma

\begin{tabular}{lllll}
\hline Type & Drug & Clinical trial identifier & Number of subjects & References \\
\hline Adenosine receptor agonists & Trabodenoson & NCT01123772 & 70 & {$[94]$} \\
& & NCT01123785 & 144 & {$[95]$} \\
& & NCT01917383 & 101 & - \\
Nitric oxide donors & NCT02565173 & 303 & - \\
& OPA-6566 & NCT01410188 & 160 & - \\
Rho Kinase inhibitors & BOL-303259-X & NCT01223378 & 396 & {$[96]$} \\
& & NCT01749904 & 421 & - \\
& AR-13324 & NCT01528787 & 85 & {$[98]$} \\
& & NCT01731002 & 213 & {$[99]$} \\
PG324 & NCT02207491 & 292 & {$[100]$} \\
& & NCT02674854 & Recruiting & - \\
& \multirow{2}{*}{ K-115 } & JAPIC090708 & 28 & {$[103]$} \\
& & JAPIC111700 & 205 & {$[104]$} \\
& & - & 92 & {$[105]$} \\
& & NCT00443924 & 14 & {$[106]$} \\
\hline
\end{tabular}

$5.8 \mathrm{~mm} \mathrm{Hg} 5 \mathrm{~h}$ after administration [40]. The same was observed in normotensive cynomolgus monkeys, where a single dose of the adenosine receptor agonists R-PIA $(100 \mu \mathrm{g})$ and CHA ( $N^{6}$-cyclohexyladenosine, $\left.500 \mu \mathrm{g}\right)$ resulted in an IOP rise of $4 \mathrm{~mm} \mathrm{Hg}$ within $30 \mathrm{~min}$, followed by an IOP reduction of $2-3.5 \mathrm{~mm} \mathrm{Hg}$ 2-6 $\mathrm{h}$ after administration [41]. Studies in rabbits and monkeys have explained the biphasic effect observed in IOP, by a mechanism that involves the activation of both adenosine A1 and $\mathrm{A} 2$ receptors, the latter being responsible for the initial IOP rise. With regard to adverse events, the use of adenosine receptor agonists can produce a mild transient anterior chamber flare, this effect being observed in monkeys treated with $250 \mu \mathrm{g}$ of R-PIA, and indicating a possible breakdown of the blood-aqueous barrier [41].

\section{Nitric Oxide Donors}

Nitric oxide (NO) is a mediator generated endogenously from L-arginine by a family of enzymes named NO synthases (NOS), and signaled via the second messenger cGMP [47]. In healthy eyes, the aqueous humour outflow pathway and ciliary muscle are sites of NO synthesis from endothelial NOS. This mechanism, however, is implicated in the abnormal IOP homeostasis in primary open-angle glaucoma (POAG) patients as well as in animal glaucoma models [63]. In POAG eyes, NO synthase activity is decreased in the TM, SC and ciliary muscle tissues suggesting a relationship with IOP elevation [64]. In contrast to normal eyes, lower levels of both NO end-products and cGMP are detected in the aqueous humour of POAG patients [65]. Although the site of NO 
activity responsible for increasing conventional outflow facility is currently unknown, a number of studies have proposed that TM cells and SC cells might be involved in this process [66-68].

Ashpole et al. [69] established that human SC cells respond to shear stress in a similar fashion to that of other vascular endothelia. In their study, SC cells reacted to physiological levels of shear stress by aligning with the direction of flow and by increasing production of NO. Interestingly, these investigators also found that SC cells isolated from glaucomatous eyes were either shear-unresponsive, or lifted from their substrate in the presence of shear stress, suggesting that NO production by SC cells exhibited a homeostatic signaling function during times of elevated IOP, when SC narrows and shear stress on SC cells increases [69]. Accordingly, NO-donating drugs may be of interest as they could provide greater and more efficient IOP control in glaucoma. To date, it has been demonstrated that NO-donating compounds effectively increase conventional outflow facility and lower IOP in mice, rabbits, pigs, dogs, monkeys, and humans [46, 67, 70].

Borghi t al. [46] evaluated the use of NCX 125 , a NO-donating latanoprost acid synthesized compound, in the rabbit, dog, and primate experimental glaucoma models. The hypotensive efficacy obtained with NCX 125 was compared with a commercial formulation of latanoprost [46]. Notably, NCX 125 exhibited greater IOP-lowering efficacy in all cases. In rabbits, the effects were maximal between 30 and $90 \mathrm{~min}$ with an IOP difference versus commercial latanoprost of $10.1 \pm 2.3 \mathrm{~mm} \mathrm{Hg}$. The pharmacokinetics of latanoprost-free acid in the aqueous and iris ciliary body after the instillation of NCX 125 compared with latanoprost did not differ significantly between study groups. In dogs, the maximum effect occurred $4 \mathrm{~h}$ after administration of NCX 125, which was significantly greater in comparison to that observed after latanoprost treatment $(-6.7 \pm 1.2$ vs. $-10.6 \pm 2.3 \mathrm{~mm} \mathrm{Hg}$, respectively). In non-human primates, NCX 125 therapy reduced IOP by $-16.7 \pm 2.2 \mathrm{~mm} \mathrm{Hg}$ ( $T_{\max } 240 \mathrm{~min}$ ), while the equivalent dose of latanoprost resulted in a smaller decline in IOP $\left(-11.9 \pm 3.7 \mathrm{~mm} \mathrm{Hg}, T_{\max } 360 \mathrm{~min}\right)$.
In a different study with NO-donating latanoprost, Krauss et al. [47] investigated the efficacy of BOL-303259-X in preclinical models of hypertensive glaucoma. The levels of latanoprost acid were measured in rabbit and primate aqueous humour, corneas, and iris/ciliary body following the topical administration of BOL-303259-X and latanoprost. Levels of latanoprost acid in all ocular compartments were elevated to a similar extent regardless of the treatment received in both rabbits and monkeys, although the limited sample size in monkeys $(n=2)$ did not allow a proper statistical evaluation of differences in this species. In the same study, IOP-lowering activity was also evaluated in an experimental canine glaucoma model, in which the peak IOP reduction was $-13.2 \pm 1.5 \mathrm{mmHg}$ and the effect was evident for at least $6 \mathrm{~h}$ post-instillation. A similar dose of latanoprost whilst significantly reducing IOP was not as effective as the NO-donating compound $(-7.1 \pm 1.8 \mathrm{mmHg})$, and demonstrated a slower onset of action. In laser-induced ocular hypertensive primates, BOL-303259-X was tested with 3.6- $\mu$ g $(0.012 \%), 9-\mu g(0.030 \%)$ and $36-\mu \mathrm{g}(0.12 \%)$ dosing. While the lowest dose was inactive when compared to the respective vehicle, doses of 9 and $36 \mu \mathrm{g}$ significantly decreased IOP with a peak reduction relative to baseline of $-15.2 \pm 4.9$ and $-13.5 \pm 3.0 \mathrm{~mm}$ $\mathrm{Hg}$, respectively. In contrast, the highest IOP reduction obtained with latanoprost, with a $30-\mu \mathrm{g}(0.10 \%)$ dosing regimen, was still inferior to that of the novel compound $(-11.9 \pm 3.8 \mathrm{~mm} \mathrm{Hg})$ [47].

In a more recent study, Impagnatiello et al. [48] compared the IOP-lowering activity of NCX 470, a novel NO-donating bimatoprost, with equivalent dosage of bimatoprost in ocular hypertensive rabbits, ocular normotensive dogs, and hypertensive non-human primates. This novel compound was effective in lowering IOP in all 3 animal models, and a repeated daily dosing of NCX 470 in dogs resulted in sustained IOP-lowering activity over time. In general, NCX 470 was around 3 times more potent than bimatoprost, as the $0.014 \%$ dose of NCX 470 was as effective as the $0.03 \%$ dose of bimatoprost $\quad(-4.8 \pm 0.5$ vs. $-3.2 \pm 0.9 \mathrm{~mm} \mathrm{Hg}$, respectively). The tested NO-donating 
bimatoprost compound lowered IOP progressively and reached maximum efficacy between 6 and $24 \mathrm{~h}$ after administration. In hypertensive non-human primates, the maximum IOP-lowering activity was obtained $24 \mathrm{~h}$ post-dosing $(-6.3 \pm 1.7 \mathrm{~mm} \mathrm{Hg})$ and was superior to that of bimatoprost $(-2.1 \pm 1.6 \mathrm{~mm} \mathrm{Hg})$.

To date, cumulative evidence with available experimental glaucoma models supports the notion that the IOP-lowering activity of NO-donating prostaglandin analogs exceeds that of commercially available prostaglandin analogs. This is thought to be owed to the concomitant action of the NO and prostaglandin moieties. However, although the therapeutic efficacy of these compounds seems beyond doubt, further research is needed to address their potential ocular toxicity and their clinical efficacy and safety in controlled studies in humans.

\section{Rho Kinase Inhibitors}

Rho Kinases (ROCKs) are serine/theronine kinases that exist as two isoforms, ROCK1 and ROCK2, and appear to have several actin cytoskeletal-related targets, which directly influence the contractile properties of TM and SC tissues. ROCKs inhibit myosin light chain phosphatase, mediating actin cytoskeletal changes and induce vasoconstriction [71]. Moreover, they stabilize filamentous actin and reduce cell migration by activating LIM kinases via phosphorylation [72]. Other targets of ROCKs comprise the phosphoprotein phosphatase inhibitor CPI-17 and the ezrin/radixin/moesin family of actin-binding proteins [27].

In humans, ROCK1 and ROCK2 tend to be expressed in the majority of tissues, including TM and ciliary muscle cells [73]. The catalytic activity of ROCKs is activated in response to Rho binding as well as binding of certain lipids, such as arachidonic acid, which is able to induce a five- to sixfold activation of the enzyme [73, 74]. RhoA is a small guanosine triphosphate GTP-binding protein that belongs to the Rho family and regulates aspects of cell shape, motility, proliferation, and apoptosis throughout the body [72]. By binding to GTP,
RhoA activates ROCK1 and ROCK2, which signal downstream molecules to polymerize actin fibers in the cardiovascular, pulmonary, and renal systems $[75,76]$. In the eye, RhoA has been detected in the optic nerve of glaucomatous eyes, supporting the relationship between Rho proteins and glaucoma pathophysiology [77]. Therefore, ROCKs may play a role in glaucoma pathogenesis, and Rho Kinase inhibitors may become a new therapeutic tool in our efforts to reduce IOP by modifying actomyosin activity [78].

The effectiveness of RhoA kinase inhibitor Y-27632 in increasing aqueous humour outflow facility was evaluated by Honjo et al. [79]. In cultured human TM cells, Y-27632 successfully induced retraction and thinning of cells after $30-60 \mathrm{~min}$, as well as a high alteration of $F$-actin distribution. Outflow facility, IOP and uveoscleral outflow were evaluated after topical, intracameral, and intravitreal administration in Japanese rabbits. By topical administration, authors reported a significant IOP decrease after $30 \mathrm{~min}$. Intracameral and intravitreal injections provided significant IOP lowering between 30 min and $24 \mathrm{~h}$. Eyes treated with Y-27632 experienced a twofold increase in outflow facility in comparison with control $(0.24 \pm 0.02$ vs. $0.12 \pm 0.01 \mu \mathrm{L} \mathrm{min}^{-1}$, respectively). With regard to safety these authors did not observe anterior chamber, lens, or fundus abnormalities by slit lamp examination for any of the three administration routes employed. In another experimental study Rosenthal et al. [80] incubated small TM strips, dissected from freshly enucleated bovine eyes, with Y-27632 to evaluate its effect on the contractility of the tissue. The initial contraction produced by endothelin-1 and carbachol was significantly reduced with a 20-min pre-incubation of the tissue with the ROCK inhibitor.

In 2009, Fukunaga et al. [81] evaluated the effect of the ROCK inhibitor HA-1077 in an animal model of ocular hypertension. For the evaluation, HA-1077 was dissolved in phosphate-buffered saline to be instilled on rabbits at 1,2 or $3 \mathrm{mM}$. These authors reported a maximal concentration-dependent IOP reduction that occurred 120 min after the instillation $(-17.4 \%,-27.3 \%$ and $-46.4 \%$, for 1,2 , and 
$3 \mathrm{mM}$, respectively). Although no abnormalities of the anterior chamber or fundus were observed, minor conjunctival hyperaemia was noticed in a few cases of eyes treated with $3 \mathrm{mM}$ HA-1077.

In a similar study, the hypotensive effect of a different ROCK inhibitor, named H-1152P, was evaluated in normal and hypertensive rabbit eyes [82]. H-1152P significantly reduced both normal and elevated IOP in these animals in a time- and dose-dependent manner. The maximum IOP-lowering effect was observed within 60-90 min after the instillation of this compound and was $-3.6 \pm 0.9,-5.4 \pm 0.7,-6.8 \pm 0.7$, and $-7.2 \pm 1.9 \mathrm{~mm} \mathrm{Hg}$, respectively, for the $0.1,1.0$, 10 , and $28 \mathrm{mM}$ dosing of $\mathrm{H}-1152 \mathrm{P}$. As regards the duration on IOP-lowering action this varied between $90 \mathrm{~min}$ and $7 \mathrm{~h}$ depending on the concentration employed and was longer with higher concentrations. No serious side effects were observed in ocular tissues, except conjunctival hyperemia observed in some cases, which disappeared within $3 \mathrm{~h}$ of application.

Following the evidence of IOP-lowering efficacy with the so-far tested ROCK inhibitors, the synthesis of new molecules is under investigation. In that respect, Henderson et al. [83] have recently published a SAR development around two hits from a kinase library that led to a number of ROCK inhibitors with sub-500 nM activity against ROCK 1 and sub- $100 \mathrm{nM}$ activity against ROCK2. One of these compounds, named 38, had a suitable profile for in vivo determinations similar to the one found for H1152. Compound 38 has demonstrated an average IOP reduction of $33 \%$ at the $300-\mu$ g dose and $37 \%$ at the $600-\mu \mathrm{g}$ dose in a hypertensive model of cymologous monkey. The topical administration of compound 38 was also associated with mild hyperemia, but no discharge or swelling were evident with this compound.

In order to improve the pharmaceutical properties of ROCK inhibitors, Yin et al. [84] have recently designed a series of urea-based ROCK2 inhibitors with SAR studies performed on the central phenyl ring and on the urea bond of the molecules. Importantly, the introduction of both electron-donating groups and electron-withdrawing groups to the central phenyl ring, at the position ortho to the urea group, generated high ROCK2 potency $(1 \mathrm{mM}$ or below) and high cellular activity. The instillation of one of these compounds, named $1 \mathrm{y}$, on Brown Norway rats, reduced IOP around $7 \mathrm{~mm}$ $\mathrm{Hg}$ compared with that of the vehicle. The IOP reduction was observed from 1 to $4 \mathrm{~h}$ and returned to baseline levels approximately $8 \mathrm{~h}$ later. According to this study, the use of ureabased ROCK inhibitors may offer a promising option for the future treatment of glaucoma. However, there is still a need to develop ocular appropriate toxicology studies to evaluate, among others, conjunctival hyperemia, a common adverse event described in long-term therapies with other ROCK inhibitors. This hyperemia is believed to derive from a smooth muscle cell relaxation of conjunctival blood vessels. It is worth noting that research efforts under way on the design and synthesis of ROCK inhibitors aim to convert them into a predictable, nontoxic metabolite by controlled metabolic inactivation. In this sense, Van de Velde and et al. [85] have evaluated the in vivo safety profile and IOP-lowering potency of AMA0076, a ROCK1 and ROCK2 inhibitor that can be inactivated by esterases, thus minimizing its effect on the ocular surface. Studies to determine the rate of conversion of AMA0076 into its functionally inactive metabolite were performed in cornea, conjunctiva, sclera, and aqueous humour, confirming that the highest specific activity was found in cornea, followed by the conjunctiva, sclera, and aqueous humour $\left(4.81, \quad 1.93, \quad 1.25, \quad 0.14 \mathrm{pmol} \mathrm{min}{ }^{-1} \mathrm{mg}^{-1}\right.$, respectively). Maximum IOP reduction compared with baseline values after a single dose of AMA0076 at a concentration of $0.5 \%, 0.3 \%$, and $0.1 \%$ was $48 \pm 0.32 \% \quad(p=0.03), 39 \pm 0.41 \%$ $(p=0.003), \quad$ and $23 \pm 0.17 \% \quad(p=0.0006)$, respectively. IOP-lowering efficacy lasted $2 \mathrm{~h}$ post-dosing for the $0.5 \%$ and $0.3 \%$ concentrations, and $4 \mathrm{~h}$ post-dosing for the $0.1 \%$ concentration. In a hypertensive rabbit model, induced by the injection of a viscous agent in the anterior chamber of the eye, the topical application of AMA0076 0.3\% and 0.5\%, completely inhibited IOP elevation $(p<0.0001)$ with minimal conjunctival hyperaemia.

Following the well-documented IOP-lowering efficacy of ROCK inhibitors in multiple 
animal models, a number of clinical trials have been developed. Further information is provided in the clinical trials section.

\section{Actin Polymerization Inhibitors}

Actin comprises a monomeric unit of microfilaments able to spontaneously polymerize into helical filaments. It is an integral part of the cytoskeleton and provides mechanical structure, motility, and contributes to a series of complex cellular activities in amoeboid and animal cells [86]. The use of molecules which can inhibit actin polymerization in conventional pathway cells is currently of great research interest. Research efforts have concentrated on exploring novel mechanisms by which either the spaces between the inner wall of SC and the trabecular collagen beams can be expanded, and/or openings between inner wall cells can be enlarged. In this sense, studies employing actin-disrupting agents, such as cytochalasans and latrunculin, have shown promising results [26, 50-52, 87].

Cytochalasans are a diverse group of fungal polyketide-amino acid hybrid metabolites with diversified distinctive biological functions. The best known property of cytochalasans is the capping of actin filaments, preventing their elongation and affecting several actin-dependent cellular events, such as cell morphogenesis, motility, and endocytosis [88]. Latrunculins are macrolides isolated from the marine sponge Latrunculia magnifica that sequester monomeric G-actin, leading to the disassembly of actin filaments and morphological changes in cells [50]. Sanka et al. [89] investigated the activity of cytochalasin D and latrunculin A on MMP-2 activation in cultured primary human confluent TM cells. Cells treated with both agents demonstrated the greatest degree of cell morphology alterations, with rounding-up of cells, cell-cell separation, and cell detachment, as well as amendments in staining patterns for F-actin. A dramatic effect on MMP-2 activation was also observed by these authors and was attributed to a reduction of the MMP- 2 proform. It has also been suggested that there is a relationship between substrate compliance and cell actin polymerization that might influence the response of human TM to latrinculin-B [90]. In non-human primates, the topical administration of latrinculin-B considerably increased outflow facility by $123 \pm 67 \%$ and $272 \pm 45 \%$, respectively with the 0.8 - and $4.0-\mu$ g doses over a 90-min period [91]. Further studies in cynomolgus monkeys and human enucleated postmortem eyes demonstrated latrunculin B to significantly enhance the conventional outflow $[25,26,50,52]$.

As demonstrated by a number of investigators, the use of actin depolymerizers results in a meaningful enhancement in outflow activity and significant improvement in effective filtration area compared with the controls. These findings have been corroborated in vivo by observing a meaningful IOP reduction after the topical administration of latrinculin-B in non-human primates. Subsequent to these experimental results, clinical trials have been initiated evaluating the safety, tolerability, and IOP-lowering efficacy of these actin depolymerizers in patients with ocular hypertension, or early POAG. For further information, see the next section.

\section{PHASE I-III CLINICAL TRIALS ON NOVEL IOP-LOWERING COMPOUNDS}

This section is focused on novel, ocular IOP-lowering compounds that are active in Phases I to III of glaucoma clinical trials within the past 2 years (until July 2016). More specifically, we briefly examine IOP-lowering therapies that focus on the mechanism of the conventional aqueous outflow in relation to ECM turnover and cell stiffness in the TM and SC (Table 2). Databases used in these searches include published articles, meeting abstracts and Clinical Trial Registry (http://www. clinicaltrials.gov).

\section{Adenosine Receptor Agonists}

Trabodenoson is a highly selective adenosine mimetic targeting the A1 receptor with the 
potential to lower IOP by increasing conventional outflow facility directly at the TM level. The administration of this novel molecule has been shown to significantly increase aqueous humour outflow facility in Dutch-Belted rabbits, ocular normotensive and hypertensive New Zealand white rabbits, and in isolated perfused porcine anterior segments [92, 93]. Subsequently, Laties et al. [94] published the tolerability and safety profile of different doses of trabodenoson in a randomized, double-masked, placebo-controlled dose escalation study, in which the drug was topically applied in healthy volunteers (aged 35-76 years) in doses varying from 200 to $3200 \mu \mathrm{g}$ [94]. Overall results were very encouraging with minimal ocular adverse events encountered that lasted less than $24 \mathrm{~h}$ and were generally mild in intensity and self-limiting. Although no anterior chamber inflammation or changes in visual acuity were noted in any of the normal subjects, the bilateral topical application of trabodenoson once daily beginning at $200 \mu \mathrm{g}$ in 1 eye and $1600 \mu \mathrm{g}$ in the fellow eye-with dose escalation every other day thereafter-was associated with a greater incidence of adverse events compared with placebo (50 vs. $25 \%$, respectively). Further analysis indicated that there was no tissue accumulation with repeated dosing, supporting continued clinical development of trabodenoson to confirm and better characterize its safety and efficacy profile in a sufficient sample of patients with POAG and ocular hypertension. Of particular interest in the future will be the effectiveness of this novel IOP-lowering compound in secondary glaucomas with worse 24 -h IOP characteristics than POAG caused by a functional blockade of the conventional outflow system (e.g. exfoliative or pigmentary glaucoma). The direct effect of trabodenoson upon the conventional outflow facility implies that the efficacy potential of this adenosine receptor agonist may be greater in these glaucomas compared with POAG.

In 2016, Myers et al. [95] in a randomized, double-marked, placebo-controlled, dose escalation study reported the efficacy and safety of 4 trabodenoson doses $(50,100,200$, and $500 \mu \mathrm{g})$ administered twice daily over 14 or 28 days in subjects with ocular hypertension, or POAG.
There were few treatment-related adverse events, mainly ocular and conjunctival hyperemia detected in 16 subjects treated with trabodenoson (18.8\%), of whom 10 subjects exhibited mild and 6 moderate hyperemia. The highest dose $(500 \mu \mathrm{g})$ was associated with the highest incidence of hyperemia, both before and after randomization. Consequently, it was suggested that the hyperemia may have been a pre-existing pathology rather than an effect of trabodenoson therapy. With regard to efficacy, a dose-dependent reduction in IOP was identified with trabodenoson. For the $500 \mu \mathrm{g}$ dosing group at day 28 , the IOP reduction ranged between -3.5 and $-5.0 \mathrm{~mm} \mathrm{Hg}$ (mean reduction of $-4.1 \mathrm{~mm} \mathrm{Hg}$ ), compared to a reduction between -1.0 and $-2.5 \mathrm{~mm} \mathrm{Hg}$ (mean reduction of $-1.6 \mathrm{~mm} \mathrm{Hg}$ ) for the corresponding placebo-treated group. Moreover, IOP lowering seemed to improve with longer exposure to therapy; IOP reduction at day 29 was significantly greater than that seen at day 14 $(p=0.0163)$. Importantly, in the $500 \mu \mathrm{g}$ dosing group, trabodenoson's IOP-lowering efficacy lasted at least $24 \mathrm{~h}$ after the last dose. Nevertheless, the 24-h efficacy of trabodenoson remains to be elucidated.

In 2015, Inotek Pharmaceuticals completed a Phase II study evaluating the adjunctive efficacy of trabodenoson to latanoprost in subjects with either ocular hypertension, or POAG (clinical trial identifier NCT01917383). To date, these results have not being published. In 2016, the same company started recruiting participants for a Phase III study (clinical trial identifier NCT02565173) that involved the topical application, in both eyes, of trabodenoson ophthalmic formulation $3.0 \%$ or $6.0 \%$ once per day, or trabodenoson $4.5 \%$ administered twice daily in adults with ocular hypertension, or POAG, with the purpose of assessing the efficacy, tolerability, and safety of trabodenoson treatment for 12 weeks, in comparison with timolol, used as active control in the study. At the same time, they have also started recruiting participants for a Phase II study to evaluate the overall benefit/ risk profile of bilateral, once-daily topical application of fixed-dose combinations of trabodenoson $(3.0 \%$ and $6.0 \%)$ and latanoprost $(0.05 \%$ or $0.0025 \%)$ in adults with ocular 
hypertension or POAG (clinical trial identifier NCT02829996).

In a separate research approach, Acucela Inc. and Otsuka Pharmaceuticals Co. have performed a Phase I-II study to evaluate the safety, tolerability, pharmacokinetics, and IOP-lowering efficacy of the adenosine A2 receptor agonist OPA-6566, in a dose-escalation study in subjects with ocular hypertension, or POAG (clinical trial identifier NCT01410188). No study results are currently available.

\section{Nitric Oxide Donors}

A phase II study to assess the efficacy and safety of latanoprost bunod, a NO-donating prostaglandin F2 $\alpha$ receptor agonist, has recently been published by Weinreb et al. [96]. The clinical trial, named the VOYAGER study (clinical trial identifier NCT01223378), was a randomized, investigator-masked, parallel-group, dose-ranged study designed to compare the efficacy and safety of 4 different concentrations of latanoprost bunod ophthalmic solution against a commercially available formulation of latanoprost $0.005 \%$ ophthalmic solution, in patients diagnosed with open-angle glaucoma (including pigmentary or exfoliative glaucoma), or ocular hypertension. A total of 396 subjects were randomized and completed this study (76 on latanoprost bunod $0.006 \%$; 81 on latanoprost bunod $0.012 \%$; 80 on latanoprost bunod $0.024 \%$; 80 on latanoprost bunod $0.040 \%$; and 79 on latanoprost $0.005 \%$ ). No difference in treatment effect between equivalent molar concentrations of either drug was detected. A dose-dependent increase in efficacy was observed with latanoprost bunod beyond the $0.006 \%$ dose and up to the $0.024 \%$ dose, revealing the dose-response curve for the NO-donating moiety of latanoprost bunod. In general, IOP reduction was significantly greater with latanoprost bunod compared with commercially available latanoprost. The safety assessment indicated that latanoprost bunod at concentrations between $0.006 \%$ and $0.040 \%$, dosed once daily for a period of 28 days, was well tolerated but was associated with a higher incidence of ocular adverse events. The most common adverse events encountered were ocular pain upon instillation and hyperemia, which were both mild to moderate in severity.

Latanoprost bunod entered a Phase 3 clinical trial, sponsored by Baush and Lomb that finished in 2015 (clinical trial identifier NCT01749904). In July 2016, the FDA did not identify any efficacy or safety concerns with respect to the New Drug Application for latanoprost bunod $0.024 \%$ ophthalmic solution. If approved, latanoprost bunod $0.024 \%$, formulation licensed by Nicox to Bauch and Lomb, would be the first once-daily nitric oxide-donating prostaglandin analog in the market which will lower IOP by increasing aqueous humour outflow through both the conventional (TM and SC) and the unconventional (uveoscleral pathway) outflow systems.

\section{Rho Kinase Inhibitors}

AR-13324 (netarsudil) is a new class of ocular hypotensive compounds that inhibits both Rho Kinase and the norepinephrine transporter. AR-13324 seems capable of obtaining a significant IOP reduction in both rabbits and monkeys, with a longer duration of action than reported for previously characterized ROCK inhibitors and a mechanism of action that combines an increase in outflow facility (by ROCK inhibition) and a concomitant decrease in aqueous humour production (by norepinephrine transporter inhibition) [97].

In 2012, Aerie Pharmaceuticals sponsored the first study in patients with elevated IOP that received ophthalmic solutions of AR-13324 (netarsudil), at 3 different concentrations $(0.01 \%, 0.02 \%$ and $0.04 \%)$, dosed once daily for a period of 7 days (clinical trial identifier NCT01528787). Netarsudil achieved a significant gradual IOP reduction for a period of $8 \mathrm{~h}$ after administration and its effect lasting for over $24 \mathrm{~h}$. Researchers detected a dose-related ocular hyperemia that declined in incidence and severity with repeated dosing [98].

More recently, Bacharach et al. [99] documented the hypotensive efficacy and safety of $0.01 \%$ and $0.02 \%$ netarsudil, compared with latanoprost ophthalmic solution used as 
positive control, in a 28-day study with PM dosing in subjects with either open-angle glaucoma, or ocular hypertension. On day 14 , mean diurnal IOP decreased from $25.8 \mathrm{~mm} \mathrm{Hg}$, $25.6 \mathrm{~mm} \mathrm{Hg}$ and $25.5 \mathrm{~mm} \mathrm{Hg}$ to $19.8 \mathrm{~mm} \mathrm{Hg}$, $19.5 \mathrm{~mm} \mathrm{Hg}$ and $18.4 \mathrm{~mm} \mathrm{Hg}$ in the $0.01 \%$ netarsudil, $0.02 \%$ netarsudil and $0.005 \%$ latanoprost groups, respectively. On day 28, netarsudil did not meet the criteria for non-inferiority compared to commercially available latanoprost. Latanoprost and $0.02 \%$ netarsudil were statistically similarly effective at all timepoints in the subset of patients with baseline IOPs $\leq 26 \mathrm{~mm} \mathrm{Hg}$, demonstrating a reduction in mean diurnal IOP of 7.7 and $5.6 \mathrm{~mm} \mathrm{Hg}$, respectively. The most frequently reported drug-related event was conjunctival/ ocular hyperemia, which was more common with netarsudil: its incidence was 52\% (39/75), $57 \%(41 / 72)$, and $16 \%(12 / 77)$ in the netarsudil $0.01 \%$, netarsudil $0.02 \%$, and latanoprost groups, respectively $(p<0.001)$. Slit-lamp examination conducted during safety visits on day 7 observed mild, or moderate conjunctival hyperemia in $28 \%(21 / 74)$ and $35 \%(25 / 72)$ of patients in the netarsudil $0.01 \%$ and $0.02 \%$ treatment groups, respectively, in contrast to only $4 \%(3 / 76)$ of patients in the latanoprost $0.005 \%$ group. Overall, conjunctival hyperemia was seen in more than half of the patients treated with netarsudil, but it was described by these investigators as transient due to the lower incidence scored by slit-lamp examination in the morning compared to the greater incidence reported by patients after dosing in the evening. However, this study did not provide information on the long-term efficacy of netarsudil, its efficacy in patients with a corneal thickness greater than $600 \mathrm{~mm}$, or in patients with other forms of glaucoma than open-angle glaucoma. These should be investigated in the future.

Aerie Pharmaceuticals has also evaluated the use of PG324 ophthalmic solution, a fixed combination of netarsudil $0.01 \%$, or $0.02 \%$ and latanoprost $0.005 \%$. A total of 292 patients were randomized to receive: (1) PG324 0.01\%, (2) PG324 0.02\%, (3) netarsudil $0.02 \%$, or (4) commercially available latanoprost $0.005 \%$ [100]. In this study, both PG324 0.02\% $(p<0.0001)$ and PG324 0.01\% $(p=0.0071$ and
0.002) fixed combinations met the criterion for statistical superiority versus the two monotherapies tested (latanoprost and netarsudil 0.02\%). All four treatments provided statistically $(p<0.0001)$ and clinically meaningful IOP decreases $(-6.2$ to $-9.1 \mathrm{~mm} \mathrm{Hg}$ ) in mean diurnal IOP from untreated baseline. Moreover, PG324 0.02\% fixed combination obtained mean IOP between 15.6 and $17 \mathrm{~mm} \mathrm{Hg}$ across all tested time points compared to mean IOP between 17.7 and $19.6 \mathrm{~mm} \mathrm{Hg}$ provided by latanoprost. Thus, the novel PG324 $0.02 \%$ fixed combination was superior to latanoprost monotherapy by $1.6-3.2 \mathrm{~mm} \mathrm{Hg}$. The greater IOP-lowering effect for PG324 persisted $36 \mathrm{~h}$ after last dosing with a difference of $2.2 \mathrm{~mm} \mathrm{Hg}$ in favor of PG324 on day 30 . The most frequently reported adverse event was mild and transient conjunctival hyperemia with an incidence of $41 \%$ and $40 \%$ for PG324 $0.01 \%$ and PG324 $0.02 \%$, respectively. In 2016, Aerie Pharmaceuticals initiated a sponsored phase III study to evaluate the ocular hypotensive efficacy and safety of the new fixed combination compared to netarsudil ophthalmic solution $0.02 \%$ and latanoprost ophthalmic solution $0.005 \%$ in patients with open-angle glaucoma or ocular hypertension (clinical trial identifier NCT02674854).

It is noteworthy that, in the last 2 years, another ROCK inhibitor has emerged as a therapeutic molecule with potential to become a future topical antiglaucoma therapy. This K-115 compound, named ripasudil, has become the first topical ROCK inhibitor developed for the treatment of glaucoma or ocular hypertension in Japan. Initially, ripasudil demonstrated a meaningful IOP-lowering effect in rabbits and monkeys [101]. Subsequently, phase I clinical studies showed its efficacy in healthy adult volunteers [102]. Furthermore, Tanihara et al. [103] conducted a multicenter, prospective, randomized, crossover study for the estimation of its IOP-lowering efficacy over $24 \mathrm{~h}$ in patients with either ocular hypertension or POAG. These authors enrolled 43 patients who received ripasudil $0.2 \%$, ripasudil $0.4 \%$, or placebo in both eyes twice a day for 3 periods separated by 5-30 days. They established statistically significant IOP reductions from baseline for both dosages of ripasudil and for placebo at all 
time-points except at $24 \mathrm{~h}$ after the first instillation ( $12 \mathrm{~h}$ after the second instillation) for the placebo group. The IOP lowering obtained varied between -2.0 and $-4.1 \mathrm{~mm} \mathrm{Hg}$ in the placebo group, -5.2 and $-6.8 \mathrm{~mm} \mathrm{Hg}$ in the $0.2 \%$ ripasudil group, and -6.4 and $-7.3 \mathrm{~mm} \mathrm{Hg}$ in the $0.4 \%$ ripasudil group, respectively, at $2 \mathrm{~h}$ after the first and the second instillation [103]. Furthermore, differences in maximum IOP reductions between placebo and ripasudil-administered patients were -3.4 and $-2.9 \mathrm{~mm} \mathrm{Hg}$ in $0.2 \%$ ripasudil group and -4.4 and $-3.3 \mathrm{~mm}$ $\mathrm{Hg}$ in the $0.4 \%$ ripasudil group, respectively, after the first and the second instillation. Conjunctival hyperemia was detected in 3 (11\%), 22 (79\%) and $27(96 \%)$ of the 28 patients, in placebo, ripasudil $0.2 \%$ and ripasudil $0.4 \%$, respectively. In most cases, however, there was only mild to moderate conjunctival hyperemia appearing within $1 \mathrm{~h}$ after instillation and only being evident for 1-3 $\mathrm{h}$.

In a phase III study, Tanihara et al. [104] conducted a 56-day, multicenter, randomized, placebo-controlled, double-masked, parallel group comparison to evaluate additive IOP-lowering effects and safety of ripasudil $0.4 \%$, in combination with timolol $0.5 \%$, or latanoprost $0.005 \%$, in patients with ocular hypertension or POAG [104]. Patients were randomly assigned to two groups and treated with ripasudil $0.4 \%$ or placebo in addition to timolol $0.5 \%$ or latanoprost $0.005 \%$. The mean baseline IOP at 0900 hours for the population analyzed was $19.8 \pm 1.8$ and $19.8 \pm 1.9 \mathrm{~mm} \mathrm{Hg}$ in the ripasudil-timolol and ripasudil-latanoprost studies, respectively.

Two hours after instillation (1100 hours) mean IOP reductions for ripasudil and placebo were -2.9 and $-1.3 \mathrm{~mm} \mathrm{Hg}$ and -3.2 and $-1.8 \mathrm{~mm} \mathrm{Hg}$, respectively, in the ripasudil-timolol and the ripasudil-latanoprost studies. Statistically significant IOP differences between ripasudil and placebo were only detected in the ripasudil-timolol study.

The most frequent adverse event described with these fixed combinations was conjunctival hyperemia, with incidence rates of $65.4 \%$ and $55.9 \%$, respectively, in the ripasudil-timolol and ripasudil-latanoprost studies. In almost all cases, the investigators considered hyperemia to be drug-related. Even though hyperemia was observed in most cases after every instillation, it should be noted that hyperemia was mild in all cases. Further, in most cases, hyperemia resolved prior to the next instillation (clinical trials Japanese identifiers JAPIC111700 and JAPIC111701).

The use of ripasudil was also evaluated in 92 glaucoma patients who could not be controlled medically despite the use of maximal tolerated medical therapy [105]. A total of 43 subjects with POAG, 28 with normal-tension glaucoma, 10 with secondary glaucoma, 7 with exfoliative glaucoma, and 4 with developmental glaucoma received ripasudil as adjunctive therapy. The mean pre-administration IOP and mean percentage of IOP reduction at the last follow-up were $19.7 \pm 4.9 \mathrm{~mm} \mathrm{Hg}$ and $6.5 \pm 17.0 \%$ for POAG, $15.5 \pm 2.0 \mathrm{~mm} \mathrm{Hg}$ and $2.3 \pm 10.4 \%$ for normal-tension glaucoma, $22.8 \pm 8.3 \mathrm{~mm} \mathrm{Hg}$ and $19.1 \pm 13.5 \%$ for secondary glaucoma, $22.5 \pm 4.4 \mathrm{~mm} \mathrm{Hg}$ and $2.1 \pm 14.5 \%$ for exfoliative glaucoma, and $20.2 \pm 8.9 \mathrm{~mm} \mathrm{Hg}$ and $11.4 \pm 23.1 \%$ for developmental glaucoma, respectively.

\section{Actin Polymerization Inhibitors}

As previously discussed, the administration of latrinculin-B alters the structural geometry of the TM, by inducing a reduction in cell-cell and cell-matrix adhesion, along with impairment of cellular contractility. Consequently, outflow facility is enhanced by a relaxation of the TM and SC, which expands the area available for fluid outflow and reduces resistance to fluid flow across the system [26, 50-52, 91]. Rasmussen et al. [106] evaluated the administration of latrinculin-B in 14 subjects diagnosed with ocular hypertension or early POAG in a phase I-II study, sponsored by Merck Sharp \& Dohme Corp. and developed by Inspire Pharmaceuticals (clinical trial identifier NCT00443924). Latrinculin-B ophthalmic solution (designated as INS115644) was evaluated in four concentrations: $0.005 \%, 0.01 \%, 0.02 \%$ and $0.05 \%$. Five single-dose instillations of INS115644 separated by approximately $12 \mathrm{~h}$ were given over a period of 3 days to evaluate safety, tolerability, and 
efficacy in a multicenter, double-masked, randomized, placebo-controlled, ascending dose study. The entry requirements for IOP were untreated IOP of $22-30 \mathrm{~mm} \mathrm{Hg}$ at $8 \mathrm{AM}(<4 \mathrm{~mm}$ $\mathrm{Hg}$ difference between eyes). Following the first instillation, $0.02 \%$ INS115644 reduced IOP by $3.8 \pm 2.25 \mathrm{~mm} \quad \mathrm{Hg} \quad(p=0.002)$, and $0.05 \%$ INS115644 by $3.9 \pm 3.1 \mathrm{~mm} \mathrm{Hg} \quad(p=0.004)$ from baseline at $4 \mathrm{~h}$ post instillation. After the fifth instillation (day 3), IOP decreased from baseline by $5.4 \pm 2.4 \mathrm{~mm} \mathrm{Hg}(p=0.004)$, a $24 \%$ reduction in IOP, in the $0.02 \%$ cohort and $2.8 \pm 2.7 \mathrm{~mm} \mathrm{Hg}(p=0.02)$, a $12 \%$ reduction, in the $0.05 \%$ cohort at $4 \mathrm{~h}$ post instillation. INS115644 did not significantly lower IOP in the treated eyes compared with contralateral, placebo-control eyes at the two lowest doses tested $(0.005 \%$ and $0.01 \%)$.

Regarding safety evaluation, adverse events consisted mainly of mild ocular redness and irritation, although transient changes in central corneal thickness were noted $4 \mathrm{~h}$ post-instillation. The largest change was an increase of $\leq 2.5 \%$ at the $0.05 \%$ dose, evaluated by authors as not statistically significant.

\section{FUTURE DIRECTIONS}

As a new strategy for the management of elevated IOP adenosine receptor agonists, nitric oxide donors, Rho Kinase inhibitors, and actin polymerization inhibitors have all been reported to offer a meaningful experimental and clinical IOP reduction, which may facilitate glaucoma management. The main drawback of current antiglaucoma medications is that they reduce IOP either by decreasing the synthesis of aqueous humor or by enhancing unconventional outflow facility. In contrast, the agents discussed in the present review act on the conventional aqueous humour outflow route. They induce structural or functional changes in the TM, SC, or both these tissues by a cascade of complex biological mechanisms that by and large require further elucidation. It is eminently logical to target the TM and SC with future therapies as these are the sites of functional or anatomical resistance in glaucoma. However, to successfully develop and commercialize agents that specifically target these tissues, there is a need first to better understand the molecular changes they induce in glaucomatous cells and the responses to substrate stiffness, as well as the mechanics of the pore formation or contractility in SC cells. Progress in these important areas will facilitate adoption of currently tested drugs and will facilitate the development of new molecules.

It should be noted that, over the years, several candidate drugs targeting SC have failed during clinical testing, usually due to insufficient efficacy (e.g. candidate drugs Y39983, AR-12286, DE-104, ATS907), or due to safety and tolerability concerns in human subjects (e.g. candidate drugs INS117548, INS-115644); [107]. Nevertheless, certain molecules described here have already provided promising experimental data and initial clinical results demonstrating potential as future glaucoma therapies (e.g. trabodenoson, OPA-6566, LTB, netarsudil, ripasudil, latrunculin-B). Nevertheless, there is a need for more comprehensive efficacy evidence (dosing studies, long-term efficacy, 24-h efficacy, efficacy in other glaucomas). Further, more conclusive evidence is needed with larger studies that should assess long-term safety and tolerability. Initial results to date suggest that these agents, although promising, may still need improvements in terms of formulation, delivery mechanisms and administration to meet desirable safety and efficacy requirements. However, the overall positive benefit-to-risk ratio and their novel mechanisms of action (targeting conventional outflow and especially SC) should enable some of them to be launched commercially and to become successful adjunctive therapies in glaucoma management. Additional, well-designed, controlled clinical trials are a vital prerequisite for their further development and ultimate clinical success.

\section{ACKNOWLEDGEMENTS}

No funding or sponsorship was received for the publication charges of this article. All named authors meet the International Committee of Medical Journal Editors (ICMJE) criteria for 
authorship for this manuscript, take responsibility for the integrity of the work as a whole, and have given final approval for the version to be published. The authors would like to acknowledge the financial support from the Sanitary Research Institute of the San Carlos Clinical Hospital, and the Ocular Pathology National Net OftaRed of the Institute of Health Carlos III.

Disclosures. Professor A.G. Konstas has received research support from Alcon, Allergan and Santen; honoraria from Alcon, Allergan, Mundipharma, Santen and had congress expenses covered by Alcon, Allergan, Santen Vianex. Authors V. Andrés-Guerrero and J. García-Feijoo have nothing to disclose.

Compliance with Ethics Guidelines. This article is based on previously conducted studies, and does not involve any new studies of human or animal subjects performed by any of the authors.

Data Availability. Data sharing is not applicable to this article as no datasets were generated or analyzed during the current study.

Open Access. This article is distributed under the terms of the Creative Commons Attribution-NonCommercial 4.0 International License (http://creativecommons.org/licenses/ by-nc/4.0/), which permits any noncommercial use, distribution, and reproduction in any medium, provided you give appropriate credit to the original author(s) and the source, provide a link to the Creative Commons license, and indicate if changes were made.

\section{REFERENCES}

1. Quigley HA, Broman AT. The number of people with glaucoma worldwide in 2010 and 2020. Br J Ophthalmol. 2006;90(3):262-7.

2. De Groef L, Van Hove I, Dekeyster E, Stalmans I, Moons L. MMPs in the trabecular meshwork: promising targets for future glaucoma therapies? Invest Ophthalmol Vis Sci. 2013;54(12):7756-63.
3. Lütjen-Drecoll E. Morphological changes in glaucomatous eyes and the role of TGFbeta2 for the pathogenesis of the disease. Exp Eye Res. 2005;81(1):1-4.

4. Weinreb RN, Aung T, Medeiros FA. The pathophysiology and treatment of glaucoma: a review. JAMA. 2014;311(18):1901-11.

5. Brubaker RF. Flow of aqueous humor in humans [The Friedenwald Lecture]. Invest Ophthalmol Vis Sci. 1991;32(13):3145-66.

6. Goel M, Picciani RG, Lee RK, Bhattacharya SK. Aqueous humor dynamics: a review. Open Ophthalmol J. 2010;4:52-9.

7. Mark HH. Aqueous humor dynamics in historical perspective. Surv Ophthalmol. 2010;55(1):89-100.

8. Civan MM, Macknight AD. The ins and outs of aqueous humour secretion. Exp Eye Res. 2004;78(3):625-31.

9. Tamm ER. The trabecular meshwork outflow pathways: structural and functional aspects. Exp Eye Res. 2009;88(4):648-55.

10. Agarwal S. Textbook of ophthalmology: New Delhi; 2002.

11. Hann CR, Vercnocke AJ, Bentley MD, Jorgensen SM, Fautsch MP. Anatomic changes in Schlemm's canal and collector channels in normal and primary open-angle glaucoma eyes using low and high perfusion pressures. Invest Ophthalmol Vis Sci. 2014;55(9):5834-41.

12. Stamer WD, Braakman ST, Zhou EH, Ethier CR, Fredberg JJ, Overby DR, et al. Biomechanics of Schlemm's canal endothelium and intraocular pressure reduction. Prog Retin Eye Res. 2015;44:86-98.

13. Lütjen-Drecoll E. Functional morphology of the trabecular meshwork in primate eyes. Prog Retin Eye Res. 1999;18(1):91-119.

14. Herrnberger L, Ebner K, Junglas B, Tamm ER. The role of plasmalemma vesicle-associated protein (PLVAP) in endothelial cells of Schlemm's canal and ocular capillaries. Exp Eye Res. 2012;105:27-33.

15. Johnson M. What controls aqueous humour outflow resistance? Exp Eye Res. 2006;82(4):545-57.

16. Bill A, Mäepea O. Mechanisms and routes of aqueous humor drainage. Principles and practice of ophthalmology. Albert DM, Jakobiec FA (eds.). St Louis: Saunders; 1995.

17. Johnson M, Shapiro A, Ethier CR, Kamm RD. Modulation of outflow resistance by the pores of the 
inner wall endothelium. Invest Ophthalmol Vis Sci. 1992;33(5):1670-5.

18. Allingham RR, de Kater AW, Ethier CR, Anderson PJ, Hertzmark E, Epstein DL. The relationship between pore density and outflow facility in human eyes. Invest Ophthalmol Vis Sci. 1992;33(5):1661-9.

19. Johnson M, Chan D, Read AT, Christensen C, Sit A, Ethier CR. The pore density in the inner wall endothelium of Schlemm's canal of glaucomatous eyes. Invest Ophthalmol Vis Sci. 2002;43(9):2950-5.

20. Sit AJ, Coloma FM, Ethier CR, Johnson M. Factors affecting the pores of the inner wall endothelium of Schlemm's canal. Invest Ophthalmol Vis Sci. 1997;38(8):1517-25.

21. Braakman ST, Read AT, Chan DW, Ethier CR, Overby DR. Colocalization of outflow segmentation and pores along the inner wall of Schlemm's canal. Exp Eye Res. 2015;130:87-96.

22. Overby DR, Zhou EH, Vargas-Pinto R, Pedrigi RM, Fuchshofer R, Braakman ST, et al. Altered mechanobiology of Schlemm's canal endothelial cells in glaucoma. Proc Natl Acad Sci USA. 2014;111(38):13876-81.

23. Peterson JA, Tian B, Bershadsky AD, Volberg T, Gangnon RE, Spector I, et al. Latrunculin-A increases outflow facility in the monkey. Invest Ophthalmol Vis Sci. 1999;40(5):931-41.

24. Sabanay I, Tian B, Gabelt BT, Geiger B, Kaufman PL. Functional and structural reversibility of $\mathrm{H}-7$ effects on the conventional aqueous outflow pathway in monkeys. Exp Eye Res. 2004;78(1):137-50.

25. Ethier CR, Read AT, Chan DW. Effects of latrunculin-B on outflow facility and trabecular meshwork structure in human eyes. Invest Ophthalmol Vis Sci. 2006;47(5):1991-8.

26. Sabanay I, Tian B, Gabelt BT, Geiger B, Kaufman PL. Latrunculin B effects on trabecular meshwork and corneal endothelial morphology in monkeys. Exp Eye Res. 2006;82(2):236-46.

27. Rao VP, Epstein DL. Rho GTPase/Rho Kinase inhibition as a novel target for the treatment of glaucoma. BioDrugs. 2007;21(3):167-77.

28. Yücel YH, Johnston MG, Ly T, Patel M, Drake B, Gümüs E, et al. Identification of lymphatics in the ciliary body of the human eye: a novel "uveolymphatic" outflow pathway. Exp Eye Res. 2009;89(5):810-9.

29. Birke K, Lütjen-Drecoll E, Kerjaschki D, Birke MT. Expression of podoplanin and other lymphatic markers in the human anterior eye segment. Invest Ophthalmol Vis Sci. 2010;51(1):344-54.

30. Hoopes SL, Willcockson HH, Caron KM. Characteristics of multi-organ lymphangiectasia resulting from temporal deletion of calcitonin receptor-like receptor in adult mice. PLoS ONE. 2012;7(9):e45261.

31. Truong TN, Li H, Hong YK, Chen L. Novel characterization and live imaging of Schlemm's canal expressing Prox-1. PLoS ONE. 2014;9(5):e98245.

32. Overby DR, Stamer WD, Johnson M. The changing paradigm of outflow resistance generation: towards synergistic models of the JCT and inner wall endothelium. Exp Eye Res. 2009;88(4):656-70.

33. Junglas B, Kuespert S, Seleem AA, Struller T, Ullmann S, Bösl $\mathrm{M}$, et al. Connective tissue growth factor causes glaucoma by modifying the actin cytoskeleton of the trabecular meshwork. Am J Pathol. 2012;180(6):2386-403.

34. Tian B, Kaufman PL. Comparisons of actin filament disruptors and Rho Kinase inhibitors as potential antiglaucoma medications. Expert Rev Ophthalmol. 2012;7(2):177-87.

35. Zhou EH, Krishnan R, Stamer WD, Perkumas KM, Rajendran K, Nabhan JF, et al. Mechanical responsiveness of the endothelial cell of Schlemm's canal: scope, variability and its potential role in controlling aqueous humour outflow. J R Soc Interface. 2012;9(71):1144-55.

36. Keller KE, Acott TS. The Juxtacanalicular region of ocular trabecular meshwork: a tissue with a unique extracellular matrix and specialized function. J Ocul Biol. 2013;1(1):3.

37. Swaminathan SS, Oh DJ, Kang MH, Ren R, Jin R, Gong $\mathrm{H}$, et al. Secreted protein acidic and rich in cysteine (SPARC)-null mice exhibit more uniform outflow. Invest Ophthalmol Vis Sci. 2013;54(3):2035-47.

38. Camras LJ, Stamer WD, Epstein D, Gonzalez P, Yuan F. Circumferential tensile stiffness of glaucomatous trabecular meshwork. Invest Ophthalmol Vis Sci. 2014;55(2):814-23.

39. Crosson CE, Gray T. Modulation of intraocular pressure by adenosine agonists. J Ocul Pharmacol. 1994;10(1):379-83.

40. Crosson CE. Adenosine receptor activation modulates intraocular pressure in rabbits. J Pharmacol Exp Ther. 1995;273(1):320-6.

41. Tian B, Gabelt BT, Crosson CE, Kaufman PL. Effects of adenosine agonists on intraocular pressure and 
aqueous humor dynamics in cynomolgus monkeys. Exp Eye Res. 1997;64(6):979-89.

42. Avila MY, Stone RA, Civan MM. A(1)-, A(2A)- and A(3)-subtype adenosine receptors modulate intraocular pressure in the mouse. Br J Pharmacol. 2001;134(2):241-5.

43. Crosson CE. Intraocular pressure responses to the adenosine agonist cyclohexyladenosine: evidence for a dual mechanism of action. Invest Ophthalmol Vis Sci. 2001;42(8):1837-40.

44. Shearer TW, Crosson CE. Adenosine A1 receptor modulation of MMP-2 secretion by trabecular meshwork cells. Invest Ophthalmol Vis Sci. 2002;43(9):3016-20.

45. Li A, Leung CT, Peterson-Yantorno K, Stamer WD, Civan MM. Cytoskeletal dependence of adenosine triphosphate release by human trabecular meshwork cells. Invest Ophthalmol Vis Sci. 2011;52(11):7996-8005.

46. Borghi V, Bastia E, Guzzetta M, Chiroli V, Toris CB, Batugo MR, et al. A novel nitric oxide releasing prostaglandin analog, NCX 125, reduces intraocular pressure in rabbit, dog, and primate models of glaucoma. J Ocul Pharmacol Ther. 2010;26(2):125-32.

47. Krauss AH, Impagnatiello F, Toris CB, Gale DC, Prasanna G, Borghi V, et al. Ocular hypotensive activity of BOL-303259-X, a nitric oxide donating prostaglandin F2 $\alpha$ agonist, in preclinical models. Exp Eye Res. 2011;93(3):250-5.

48. Impagnatiello F, Toris CB, Batugo M, Prasanna G, Borghi $\mathrm{V}$, Bastia $\mathrm{E}$, et al. Intraocular pressure-lowering activity of NCX 470, a novel nitric oxide-donating bimatoprost in preclinical models. Invest Ophthalmol Vis Sci. 2015;56(11):6558-64.

49. Williams RD, Novack GD, van Haarlem T, Kopczynski C. Group A-PAS. Ocular hypotensive effect of the Rho Kinase inhibitor AR-12286 in patients with glaucoma and ocular hypertension. Am J Ophthalmol. 2011;152(5):834-41.e1.

50. Peterson JA, Tian B, McLaren JW, Hubbard WC, Geiger B, Kaufman PL. Latrunculins' effects on intraocular pressure, aqueous humor flow, and corneal endothelium. Invest Ophthalmol Vis Sci. 2000;41(7):1749-58.

51. Wakatsuki T, Schwab B, Thompson NC, Elson EL. Effects of cytochalasin D and latrunculin B on mechanical properties of cells. J Cell Sci. 2001;114(Pt 5):1025-36.

52. Okka M, Tian B, Kaufman PL. Effect of low-dose latrunculin $\mathrm{B}$ on anterior segment physiologic features in the monkey eye. Arch Ophthalmol. 2004;122(10):1482-8.

53. Chen J, Runyan SA, Robinson MR. Novel ocular antihypertensive compounds in clinical trials. Clin Ophthalmol. 2011;5:667-77.

54. Roth S, Rosenbaum PS, Osinski J, Park SS, Toledano AY, Li B, et al. Ischemia induces significant changes in purine nucleoside concentration in the retina-choroid in rats. Exp Eye Res. 1997;65(6):771-9.

55. Agarwal R, Agarwal P. Newer targets for modulation of intraocular pressure: focus on adenosine receptor signaling pathways. Expert Opin Ther Targets. 2014;18(5):527-39.

56. Mitchell CH, Carré DA, McGlinn AM, Stone RA, Civan MM. A release mechanism for stored ATP in ocular ciliary epithelial cells. Proc Natl Acad Sci USA. 1998;95(12):7174-8.

57. Braun JS. Ecto-5'-nucleotidase-positive cells in the choroid and ciliary body of the rat eye. Anat Rec (Hoboken). 2010;293(3):379-82.

58. Li A, Leung CT, Peterson-Yantorno K, Stamer WD, Mitchell CH, Civan MM. Mechanisms of ATP release by human trabecular meshwork cells, the enabling step in purinergic regulation of aqueous humor outflow. J Cell Physiol. 2012;227(1):172-82.

59. Li A, Zhang X, Zheng D, Ge J, Laties AM, Mitchell $\mathrm{CH}$. Sustained elevation of extracellular ATP in aqueous humor from humans with primary chronic angle-closure glaucoma. Exp Eye Res. 2011;93(4):528-33.

60. Zhang X, Li A, Ge J, Reigada D, Laties AM, Mitchell $\mathrm{CH}$. Acute increase of intraocular pressure releases ATP into the anterior chamber. Exp Eye Res. 2007;85(5):637-43.

61. Daines BS, Kent AR, McAleer MS, Crosson CE. Intraocular adenosine levels in normal and ocular-hypertensive patients. J Ocul Pharmacol Ther. 2003;19(2):113-9.

62. Zhong Y, Yang Z, Huang WC, Luo X. Adenosine, adenosine receptors and glaucoma: an updated overview. Biochim Biophys Acta. 2013;1830(4):2882-90.

63. Nathanson JA, McKee M. Alterations of ocular nitric oxide synthase in human glaucoma. Invest Ophthalmol Vis Sci. 1995;36(9):1774-84.

64. Nathanson JA, McKee M. Identification of an extensive system of nitric oxide-producing cells in the ciliary muscle and outflow pathway of the human eye. Invest Ophthalmol Vis Sci. 1995;36(9):1765-73. 
65. Doganay S, Evereklioglu C, Turkoz Y, Er H. Decreased nitric oxide production in primary open-angle glaucoma. Eur J Ophthalmol. 2002;12(1):44-8.

66. Ellis DZ, Sharif NA, Dismuke WM. Endogenous regulation of human Schlemm's canal cell volume by nitric oxide signaling. Invest Ophthalmol Vis Sci. 2010;51(11):5817-24.

67. Stamer WD, Lei Y, Boussommier-Calleja A, Overby DR, Ethier CR. eNOS, a pressure-dependent regulator of intraocular pressure. Invest Ophthalmol Vis Sci. 2011;52(13):9438-44.

68. Dismuke WM, Liang J, Overby DR, Stamer WD. Concentration-related effects of nitric oxide and endothelin-1 on human trabecular meshwork cell contractility. Exp Eye Res. 2014;120:28-35.

69. Ashpole NE, Overby DR, Ethier CR, Stamer WD. Shear stress-triggered nitric oxide release from Schlemm's canal cells. Invest Ophthalmol Vis Sci. 2014;55(12):8067-76.

70. Kotikoski H, Vapaatalo H, Oksala O. Nitric oxide and cyclic GMP enhance aqueous humor outflow facility in rabbits. Curr Eye Res. 2003;26(2):119-23.

71. Uehata M, Ishizaki T, Satoh H, Ono T, Kawahara T, Morishita T, et al. Calcium sensitization of smooth muscle mediated by a Rho-associated protein kinase in hypertension. Nature. 1997;389(6654):990-4.

72. Riento K, Ridley AJ. Rocks: multifunctional kinases in cell behaviour. Nat Rev Mol Cell Biol. 2003;4(6):446-56.

73. Ishizaki T, Maekawa M, Fujisawa K, Okawa K, Iwamatsu A, Fujita A, et al. The small GTP-binding protein Rho binds to and activates a $160 \mathrm{kDa}$ Ser/ Thr protein kinase homologous to myotonic dystrophy kinase. EMBO J. 1996;15(8):1885-93.

74. Feng J, Ito M, Kureishi Y, Ichikawa K, Amano M, Isaka $\mathrm{N}$, et al. Rho-associated kinase of chicken gizzard smooth muscle. J Biol Chem. 1999;274(6):3744-52.

75. Wettschureck N, Offermanns S. Rho/Rho-kinase mediated signaling in physiology and pathophysiology. J Mol Med (Berl). 2002;80(10):629-38.

76. Shimizu T, Liao JK. Rho Kinases and cardiac remodeling. Circ J. 2016;80(7):1491-8.

77. Goldhagen B, Proia AD, Epstein DL, Rao PV. Elevated levels of RhoA in the optic nerve head of human eyes with glaucoma. J Glaucoma. 2012;21(8):530-8.

78. Donegan RK, Lieberman RL. Discovery of molecular therapeutics for glaucoma: challenges, successes, and promising directions. J Med Chem. 2016;59(3):788-809.

79. Rao PV, Deng PF, Kumar J, Epstein DL. Modulation of aqueous humor outflow facility by the Rho Kinase-specific inhibitor Y-27632. Invest Ophthalmol Vis Sci. 2001;42(5):1029-37.

80. Rosenthal R, Choritz L, Schlott S, Bechrakis NE, Jaroszewski J, Wiederholt M, et al. Effects of ML-7 and Y-27632 on carbachol- and endothelin-1-induced contraction of bovine trabecular meshwork. Exp Eye Res. 2005;80(6):837-45.

81. Fukunaga T, Ikesugi K, Nishio $M$, Sugimoto $M$, Sasoh M, Hidaka H, et al. The effect of the Rho-associated protein kinase inhibitor, HA-1077, in the rabbit ocular hypertension model induced by water loading. Curr Eye Res. 2009;34(1):42-7.

82. Nishio M, Fukunaga T, Sugimoto M, Ikesugi K, Sumi $\mathrm{K}$, Hidaka $\mathrm{H}$, et al. The effect of the H-1152P, a potent Rho-associated coiled coil-formed protein kinase inhibitor, in rabbit normal and ocular hypertensive eyes. Curr Eye Res. 2009;34(4):282-6.

83. Henderson AJ, Hadden M, Guo C, Douglas N, Decornez H, Hellberg MR, et al. 2,3-Diaminopyrazines as Rho Kinase inhibitors. Bioorg Med Chem Lett. 2010;20(3):1137-40.

84. Yin Y, Cameron MD, Lin L, Khan S, Schröter T, Grant W, et al. Discovery of potent and selective urea-based ROCK inhibitors and their effects on intraocular pressure in rats. ACS Med Chem Lett. 2010;1(4):175-9.

85. Van de Velde S, Van Bergen T, Sijnave D, Hollanders K, Castermans K, Defert O, et al. AMA0076, a novel, locally acting Rho Kinase inhibitor, potently lowers intraocular pressure in New Zealand white rabbits with minimal hyperemia. Invest Ophthalmol Vis Sci. 2014;55(2):1006-16.

86. Pollard TD, Cooper JA. Actin, a central player in cell shape and movement. Science. 2009;326(5957):1208-12.

87. Spector I, Braet F, Shochet NR, Bubb MR. New anti-actin drugs in the study of the organization and function of the actin cytoskeleton. Microsc Res Tech. 1999;47(1):18-37.

88. Scherlach K, Boettger D, Remme N, Hertweck C. The chemistry and biology of cytochalasans. Nat Prod Rep. 2010;27(6):869-86.

89. Sanka K, Maddala R, Epstein DL, Rao PV. Influence of actin cytoskeletal integrity on matrix metalloproteinase- 2 activation in cultured human trabecular meshwork cells. Invest Ophthalmol Vis Sci. 2007;48(5):2105-14. 
90. McKee CT, Wood JA, Shah NM, Fischer ME, Reilly CM, Murphy CJ, et al. The effect of biophysical attributes of the ocular trabecular meshwork associated with glaucoma on the cell response to therapeutic agents. Biomaterials. 2011;32(9):2417-23.

91. Peterson JA, Tian B, Geiger B, Kaufman PL. Effect of latrunculin-B on outflow facility in monkeys. Exp Eye Res. 2000;70(3):307-13.

92. Kim N, Crosson C, Lan T, Christian B, Brusse C, Cantone G, et al. INO-8875, an Adenosine A1 Agonist, lowers intraocular pressure through the conventional outflow pathway. Investigative Ophthalmology and Visual Science2010. p. ARVO E-Abstract 3238.

93. Kim N, Crosson C, Supuran T, McCauley T, Southan $\mathrm{G}$, Baumgartner R, et al. INO-8875, An adenosine A1 agonist, in development for open-angle glaucoma reduces IOP in three rabbit models. Investigative Ophthalmology Visual Science2009. p. ARVO E-Abstract 4061.

94. Laties A, Rich CC, Stoltz R, Humbert V, Brickman C, McVicar W, et al. A randomized phase 1 dose escalation study to evaluate safety, tolerability, and pharmacokinetics of trabodenoson in healthy adult volunteers. J Ocul Pharmacol Ther. 2016;32(8):548-54.

95. Myers JS, Sall KN, DuBiner H, Slomowitz N, McVicar W, Rich CC, et al. A dose-escalation study to evaluate the safety, tolerability, pharmacokinetics, and efficacy of 2 and 4 weeks of twice-daily ocular trabodenoson in adults with ocular hypertension or primary open-angle glaucoma. J Ocul Pharmacol Ther. 2016;32(8):555-62.

96. Weinreb RN, Ong T, Scassellati Sforzolini B, Vittitow JL, Singh K, Kaufman PL, et al. A randomised, controlled comparison of latanoprostene bunod and latanoprost $0.005 \%$ in the treatment of ocular hypertension and open angle glaucoma: the VOYAGER study. Br J Ophthalmol. 2015;99(6):738-45.

97. Wang RF, Williamson JE, Kopczynski C, Serle JB. Effect of $0.04 \%$ AR-13324, a ROCK, and norepinephrine transporter inhibitor, on aqueous humor dynamics in normotensive monkey eyes. J Glaucoma. 2015;24(1):51-4.

98. Weiss M, Levy B, Kopczynski C, Van Haarlem T, Novack G. Evaluation of AR-13324, a novel dual mechanism agent, in lowering of IOP in glaucoma and ocular hypertension. ARVO Annual Meeting Abstract2013. p. 754.
99. Bacharach J, Dubiner HB, Levy B, Kopczynski CC, Novack GD. Group A-CS. Double-masked, randomized, dose-response study of AR-13324 versus latanoprost in patients with elevated intraocular pressure. Ophthalmology. 2015;122(2):302-7.

100. Lewis RA, Levy B, Ramirez N, Kopczynski CC, Usner DW, Novack GD, et al. Fixed-dose combination of AR-13324 and latanoprost: a double-masked, 28-day, randomised, controlled study in patients with open-angle glaucoma or ocular hypertension. Br J Ophthalmol. 2016;100(3):339-44.

101. Isobe $\mathrm{T}$, Mizuno $\mathrm{K}$, Kaneko $\mathrm{Y}$, Ohta M, Koide T, Tanabe S. Effects of K-115, a rho-kinase inhibitor, on aqueous humor dynamics in rabbits. Curr Eye Res. 2014;39(8):813-22.

102. Tanihara $H$, Inoue $T$, Yamamoto $T$, Kuwayama $Y$, Abe $H$, Araie $M$, et al. Phase 1 clinical trials of a selective Rho Kinase inhibitor, K-115. JAMA Ophthalmol. 2013;131(10):1288-95.

103. Tanihara $H$, Inoue $T$, Yamamoto $T$, Kuwayama $Y$, Abe $H$, Suganami $H$, et al. Intra-ocular pressure-lowering effects of a Rho Kinase inhibitor, ripasudil (K-115), over 24 hours in primary open-angle glaucoma and ocular hypertension: a randomized, open-label, crossover study. Acta Ophthalmol. 2015;93(4):e254-60.

104. Tanihara $H$, Inoue $T$, Yamamoto $T$, Kuwayama $Y$, Abe $\mathrm{H}$, Suganami $\mathrm{H}$, et al. Additive intraocular pressure-lowering effects of the Rho Kinase inhibitor ripasudil (K-115) combined with timolol or latanoprost: a report of 2 randomized clinical trials. JAMA Ophthalmol. 2015;133(7):755-61.

105. Sato S, Hirooka K, Nitta E, Ukegawa K, Tsujikawa A. Additive intraocular pressure lowering effects of the Rho Kinase inhibitor, ripasudil in glaucoma patients not able to obtain adequate control after other maximal tolerated medical therapy. Adv Ther. 2016;33(9):1628-34.

106. Rasmussen CA, Kaufman PL, Ritch R, Haque R, Brazzell RK, Vittitow JL, Latrunculin B. Reduces intraocular pressure in human ocular hypertension and primary open-angle glaucoma. Transl Vis Sci Technol. 2014;3(5):1.

107. Wang SK, Chang RT. An emerging treatment option for glaucoma: Rho Kinase inhibitors. Clin Ophthalmol. 2014;8:883-90. 